\title{
Design and Implementation of a Smart Controller in Agriculture for Improved Productivity
}

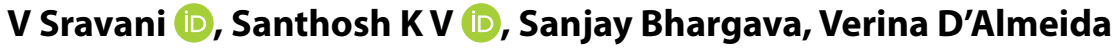 \\ Department of Instrumentation and Control Engineering, Manipal Institute of Technology, Manipal Academy of Higher Education, Manipal, India
}

Cite this article as: $\mathrm{V}$. Sravani, S. K. V., S. Bhargava, V. D'Almeida. "Design and Implementation of a Smart Controller in Agriculture for Improved Productivity". Electrica, vol. 18, no. 1, pp. 45-51,2018.

\begin{abstract}
Agricultural produce significantly depends on many crop parameters such as humidity, pH, temperature, sunlight, microbial activity, soil ions, air quality, and water quality. A higher production of crop can be achieved via maintaining all these parameters in the desired range. A smart system was developed to control the environmental parameters in the desired range via incorporating a multisensor to measure the parameters such as humidity, temperature, and sunlight; in addition, also a suitable controller was designed to control these parameters in the desired range. Sensors were placed to continuously monitor the field parameters such as temperature, humidity, sunlight, and soil moisture. All these parameters were remotely acquired using ZigBee to PC through myRIO boards. Fuzzy-based controllers were designed to operate the actuators to maintain the set point. The designed system on implementation was tested on a real-life model. The results show that the proposed technique maintained the parameters at the desired state and reduced human intervention and labor.
\end{abstract}

Keywords: Agriculture, fuzzy, humidity, light, soil moisture, temperature

Address for Correspondence:

Santhosh KV

\section{E-mail:}

kv.santhu@gmail.com

Received: 13.09.2017

Accepted: 24.10 .2017

(c) Copyright 2018 by Electrica

Available online at

http://dergipark.gov.tr/iujeee

DOI: 10.5152/iujeee.2018.1808

\section{Introduction}

The Agricultural production of any country is predominantly volatile and depends on varied factors. The changing rainfall patterns, extreme variations in temperatures, soil and air quality have significant impact on the production yield. The rain-fed agricultural production system is vulnerable to seasonal variability which affects the livelihood of the farmers and landless laborers who depend on this system. Moreover population has significantly increased over past two decades, this led to urban land expansion due to increase in urban population which caused the degradation of agricultural land which in turn has affected the production of food growth. Hence various techniques have come into existence to increase the productivity by enhancing the natural and biological processes above and below the ground. Like in [1], discusses the influence of science and technology on agriculture in Africa. One way to increase the production and benefit the farmers is by continuously monitoring climatic parameters and notify them with present weather condition so that immediate action can be taken manually or automatically for the benefit of the crop. The parameters which are continuously monitored are temperature, soil moisture, light and humidity [2]. Due to advancement in field of science and technology, efficient sensors for all required ranges are available in the market with different sizes and different measurement principles. Technology also has led to wireless transmission of data from the sensors to remote location and without the intervention of humans, parameters can be controlled and monitored which has led to agricultural automation. Wireless sensor networks are most commonly used these day for continuous monitoring of the crops.

As food is essential for human survival, there is lot of work going in particular area to enhance the productivity and meet the demands of the people. There are several issues which are to be addressed for agricultural growth like climatic changes, drought, soil infertility etc. Authors in [3] have tried to address this issue by motivating farmers of one particular region to adopt climate-smart agriculture (CSA) technologies which focuses on productivity, mitiga- 
tion in agriculture based on climatic conditions using different techniques under water-smart, energy-smart, nutrient-smart, carbon-smart, weather-smart, knowledge-smart technologies. As an extension to this proposed work in [4], authors have reported the rapid appraisal of climate smart agriculture system to discuss the influence of climate on agriculture. Authors in [5] have stated that the crop rotation can be one of the way to increase yield from crops and concluded that when winter wheat is grown after pea and winter barley crop, production of winter wheat is improved under varying climatic conditions.

The system approach to any problem always give a better idea to solve it, based on the same approach, agriculture also have different agriculture system models, which are discussed in [6], practiced from the year 1960 to present. They have stated that synchronization of these models with decision support systems can really help the society in terms of meeting the agricultural demands. In [7], use of technology acceptance model for precision agriculture. Authors in [8], talks about precision agriculture using Wireless Sensor Network (WSN) by placing sensor nodes at points, which have optimal periodic threshold sensitivity, region-based hybrid routing protocol and the data from the sensor node is passed to base station only when the parameters exceeds the threshold value there by reducing energy consumption by continuously sending the data. Development of a wireless sensor and actuation network based on decision support system which in turn realizes on fuzzy logic mimicking the farmer's action based on past experience for better water management is reported in [9]. Optimization of sensor data for precision agriculture monitoring for computing normalized difference vegetation index using sprectral response is reported in [10]. In [11], have reported use of thermal imaging to identify the requirements of water in a particular field and using cloud of things network which include internet of things and cyber physical system irrigation was done. Cloud computing based remote sensing application for soil moisture mapping is disscued in [12], for helping farmer in precision agriculture. In [13], use of Unmanned Aerial Vehicle (UAV) and Unmanned Ground Vehicle (UGV) for collection of soil data is reported. In [14], design of precision agriculture sensing system based on wireless multimedia sensor network is reported. They have formed a network of multiple sensors along with CMOS image sensor ,which is used to identify the diseases in crop and transmission of data was done using bitmap index based reliable data transmission protocol. Paper [15], said that plant productivity gets affected by soil moisture and atmospheric humidity in arid and semi-arid grassland systems. In [16], have reported design of fuzzy controller using MATLAB for automated land irrigation in simulation tool. The inputs to the fuzzy controller were taken as water level and time (day, afternoon, night) and outputs of the controller are tube well operation and power source (solar, hybrid, grid). Paper [17], have considered greenhouse control problem as non-linear and multi-variable. The performance of four different controllers was compared namely Proportional Integral Derivative (PID), Linear Quadratic Regulator (LQR), fuzzy PID, fuzzy immune PID controller taking air humidity and temperature as variables. From their experimental results they found that fuzzy immune PID gives better performance. Authors in [18], have stated that extreme temperature effect will certainly effect the plant in their reproductive stage and have significant impact on production of food grains and fruit. In [19], authors have examined impact of frost and heat shock on a wheat crop during different stages of its growth and using this information process-based crop models were formulated. Paper [20], discusses the impact of temperature and carbon dioxide on productivity of wheat and rice crop. In [21], a study to choose an ideal crop among apple, tomato, wheat and white potato for efficient use of the available land resources based on multiple aspects (climatic conditions) influencing simultaneously using Analytical Hierarchy Process (AHP) are reported. All the above reported literture discusses the current growth in precision or smart agriculture, as an initiative we are proposing a technique for monitoring of plant growth, by sensing the paramters influencing plant growth like soil moisture, humidity, sun light, and temperature. Further on take necssary action to manntain optimal parameters for good yeild in crops, if not in desirable range by implementing smart controllers.

\section{Problems in conventional agriculture}

The process of conventional agriculture system is: preparation of soil, sowing of seeds, adding manure and fertilizers, irrigation, harvesting and storage. All these steps are carried out with human intervention, which is a tedious task and each of the process requires a particular condition for having an efficient crop which produces maximum yield. The following are the challenges faced by the farmer these days:

i) Supplying adequate amount of water and fertilizers to the crop. ii) Continuously predict the climatic conditions to take necessary action.

If the above stated challenges are not properly addressed by the farmer it will affect the yield from the crops in terms of quality and quantity. The excess amount of water and fertilizer used in cultivation may also damage the quality of the soil for the future use and will also lead to water shortage when required. It is also troublesome for the farmer to track the variations in climate as changes are sudden and difficult to predict.

If this conventional system is supported by technology then problems faced by farmers can be reduced and there will be significant growth in production of food grains to meet the demands of growing population. In view of all these, this paper aims at presenting a technology which can be an aid to farmers. The objectives of proposed technique are:

1) To make use of different sensors to monitor the current condition of the agricultural field.

2) To design a control algorithm, which will reduce the human intervention and increase the productivity as well as optimal use of water is done. 


\section{Methodology}

This paper aims to provide a solution to difficulties faced by the farmer with the help of the smart agricultural monitoring technique. This paper focuses about measurement of four different parameters for monitoring the climatic conditions of the field namely temperature, light, humidity and soil moisture. The mentioned parameters will be grouped in two sets, first set consisting of temperature - light and second set with humidity-soil moisture which will form inputs to fuzzy rules and give out two outputs in terms controlling the speed of water pump and closing and opening of the shutter covering the specific area of interest. The fuzzy rule base is formed specifically for the two crops, rice and wheat, being staple food of the people. The proposed work is divided into two parts: 1) Data acquisition and 2) Control algorithm. The Figure 1, gives an overview of the proposed work. Data acquisition discusses about the sensors and other equipment's used for monitoring the current state of the crop. The control algorithm is a decision support system used to take necessary actions to meet the requirements of the crops for the proper growth.

\section{Sensors}

Temperature sensor: LM35 is used as the temperature sensor in the propsoed work, because of its sensitivtiy of $10 \mathrm{mV} /{ }^{\circ} \mathrm{C}$. Operating range of -55 to $105^{\circ} \mathrm{C}$. Figure 2 shows the schematic of used temperature sensor.

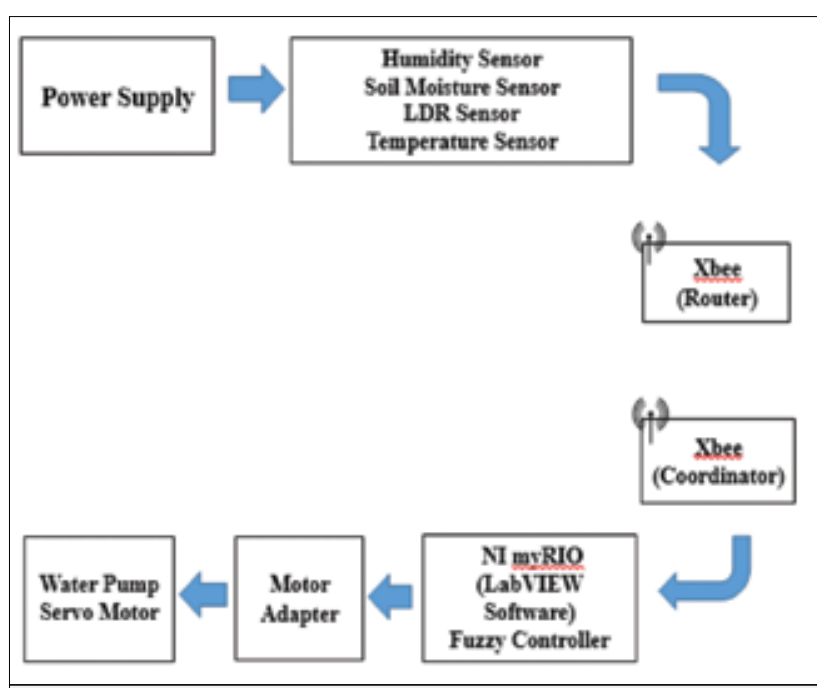

Figure 1. Block diagram of the proposed system

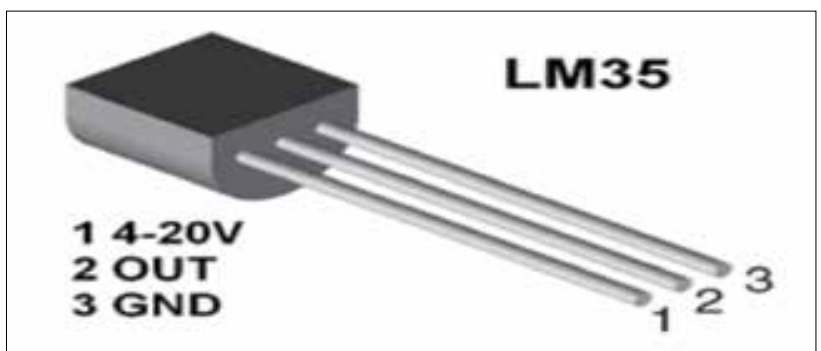

Figure 2. Temperature sensor
Light sensor: Light dependent resistor SEN133322 is used for sensing the light, light intensity is computed in lux. Lux is estimated based on change in resistance of light dependent resistor (LDR). Photosynthetically Available Radiation (PAR), PAR $=($ Lux/54). Figure 3 shows the schematic of the light sensor used in the proposed work.

Humidity sensor: Capacitive sensor $\mathrm{HIH}-4000$ is used for measuring humidty in the proposed work, because of its range of 0 to $100 \% \mathrm{RH}$. Figure 4 shows the representation of humidity sensor considered in the proposed work.

Soil moisture sensor: Conductive probe sensor is used to measure moisture content in soil. The conductive probe produces an output of 0 to $4.8 \mathrm{~V}$. Figure 5 shows the representation of the soil moisture sensor considered.

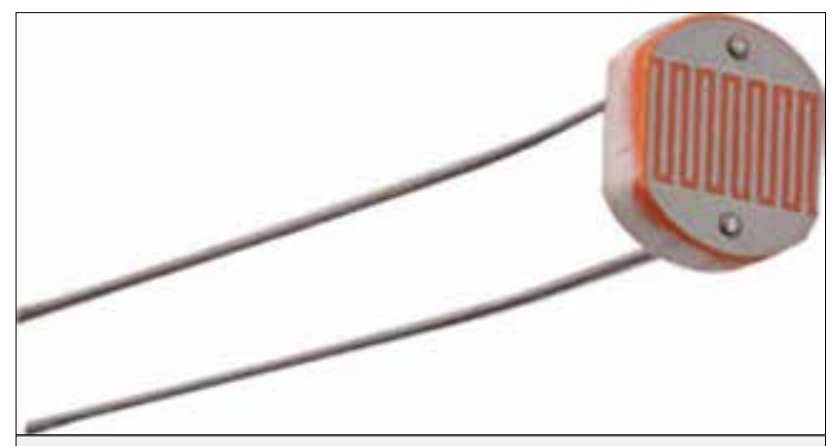

Figure 3. Light sensor

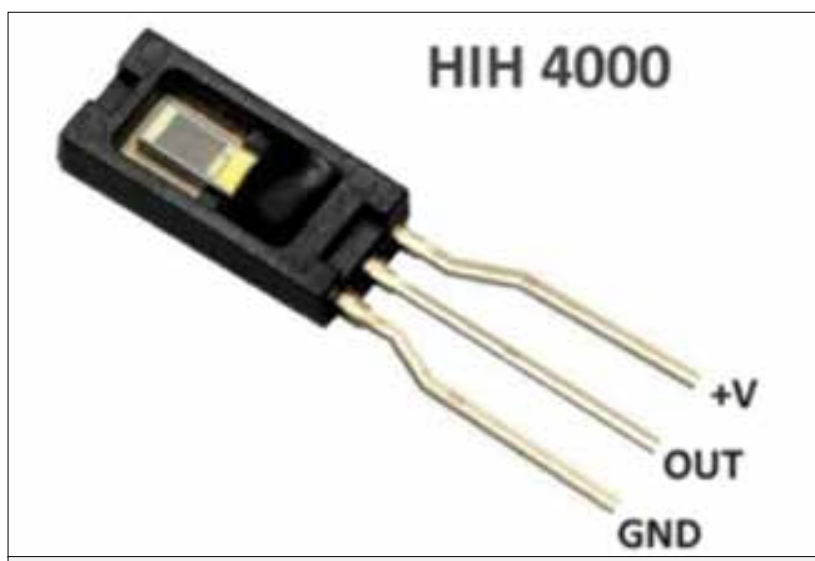

Figure 4. Block diagram of the proposed system

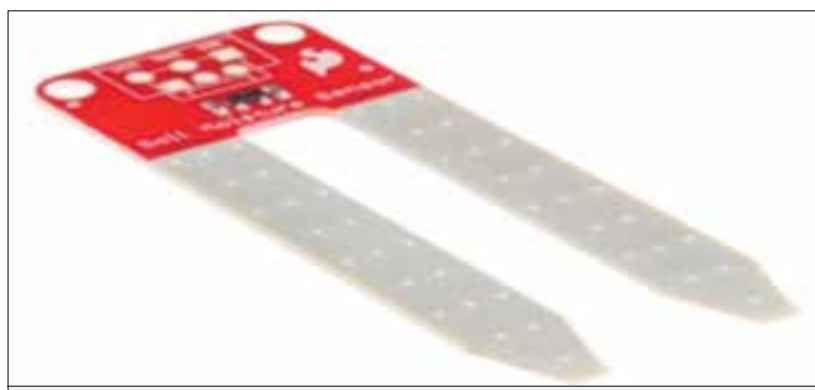

Figure 5. Block diagram of the proposed system 


\section{Data acquisition}

The field parameters like humidity, moisture, light and temperature are collected from calibrated sensors to the RIO board via ZigBee communication for wireless transmission. The details of the sensors used is mentioned in Table 1. The output from the light sensor is converted to PAR from Lux as plant biologist consider this as more suitable unit for measurement of

Table 1. Fuzzy rules for rice

\begin{tabular}{cccc}
\hline$\#$ & Temperature & Light & Servo motor \\
\hline 1 & Low & Low & Open \\
\hline 2 & Low & Medium & Open \\
\hline 3 & Low & High & Open \\
\hline 4 & Medium & Low & Open \\
\hline 5 & Medium & Medium & Partially open \\
\hline 6 & Medium & High & Close \\
\hline 7 & High & Low & Partially open \\
\hline 8 & High & Medium & Close \\
\hline 9 & High & High & Close \\
\hline
\end{tabular}

\begin{tabular}{lccc}
\hline & Humidity & Soil moisture & Water pump \\
\hline 10 & Low & Low & Open \\
\hline 11 & Low & Medium & Open \\
\hline 12 & Low & High & Open \\
\hline 13 & Medium & Low & Open \\
\hline 15 & Medium & Medium & Partially open \\
\hline 16 & Medium & High & Close \\
\hline 17 & High & Low & Partially open \\
\hline 18 & High & Medium & Close \\
\hline
\end{tabular}

Table 2. Parameter ranges for rice

\begin{tabular}{lccc}
\hline $\begin{array}{l}\text { Sensing } \\
\text { parameter }\end{array}$ & Low & Medium & High \\
\hline Temperature & $8-26^{\circ} \mathrm{C}$ (cold) & $25-35^{\circ} \mathrm{C}$ & $33-50^{\circ} \mathrm{C}$ (hot) \\
\hline Light & $0-1000$ (dark) & $800-1800$ & $\begin{array}{c}1500-2500 \\
\text { (bright) }\end{array}$ \\
\hline Humidity & $0-50$ (dry) & $40-75$ & $\begin{array}{c}70-100 \\
\text { (humid) }\end{array}$ \\
\hline Soil moisture & $0-2$ (dry) & $1.5-3.5$ & $3-5$ (wet) \\
\hline
\end{tabular}

light. These sensors continuously monitor the field and transfer data wirelessly using ZigBee router (Xbee S2C) based on the IEEE 802.15.4 standard. XCTU software is used to configure ZigBee. The ZigBee (Router) is configured and paired with the other ZigBee (coordinator). The data is sent through Application program interface (API) mode. The analog data from the sensor is converted into digital form by ZigBee. The Analog to digital converter $(A D C)$ on ZigBee radios are 10-bit. Each ADC inputs will have a separate 2 byte field in hexadecimal format in an API frame which is visible on console of XCTU software of ZigBee router and the same API frame is transmitted to ZigBee coordinator. The $A D C$ value of voltage level is given by (1):

$$
\text { Voltage, } V=\frac{A D C}{1024} * 1.2
$$

The coordinator ZigBee is connected to $\mathrm{NI}$ myRIO through UART. All the other necessary wirings are done from each of the components to the $\mathrm{NI}$ myRIO using adapters and power supply. Through NI myRIO data is acquired for further processing in LabVIEW.

The Wi-Fi of NI myRIO is connected to the PC to monitor all the parameters from a remote place. The real time program which is written on the LabVIEW is executed on the computer. The program starts and displays the values on the front panel. The sensors provide signals to ZigBee transmitter continuously and this sends the information regarding the atmosphere and the soil status remotely to the myRIO via ZigBee receiver. The system can be re-configured remotely depending on the soil and atmosphere conditions.

\section{Control Algorithm}

The climatic and soil conditions will have significant impact on the growth of the crops hence there is a need to have optimum values of temperature, light, soil moisture and air humidity. It is known that temperature- light have a collective impact on the heat requirements of the crops and air humidity-soil moisture have on necessary water requirement. This dependence has led to selection of fuzzy controller for optimizing the desired needs of the crops. Two different sets of Multi-Input-Single Output (MISO) fuzzy controllers are designed to analyze data received by various sensors. Two fuzzy controllers are defined based on the temperature and light for crops: Wheat and Rice which are the input membership functions shown in Figure 6, 7. Servo motor (considered as roof for a prototype) which rotates for a particular angle is the output membership function. Another fuzzy controller is defined based on the humidity and soil moisture requirement for both the crops which is the input membership functions and variation in pump is the output membership function. Since Humidity and Soil Moisture requirement for both the crops are almost same, only one fuzzy controller is designed for both. The sensor values when taken as input membership functions are categorized under three labels: high, medium and low. The output membership functions are defined as open, close, and partially open. Table 1 specifies about the rules chosen to form triangular membership function. Table 2 shows the parameters consider for cultivation of rice. 


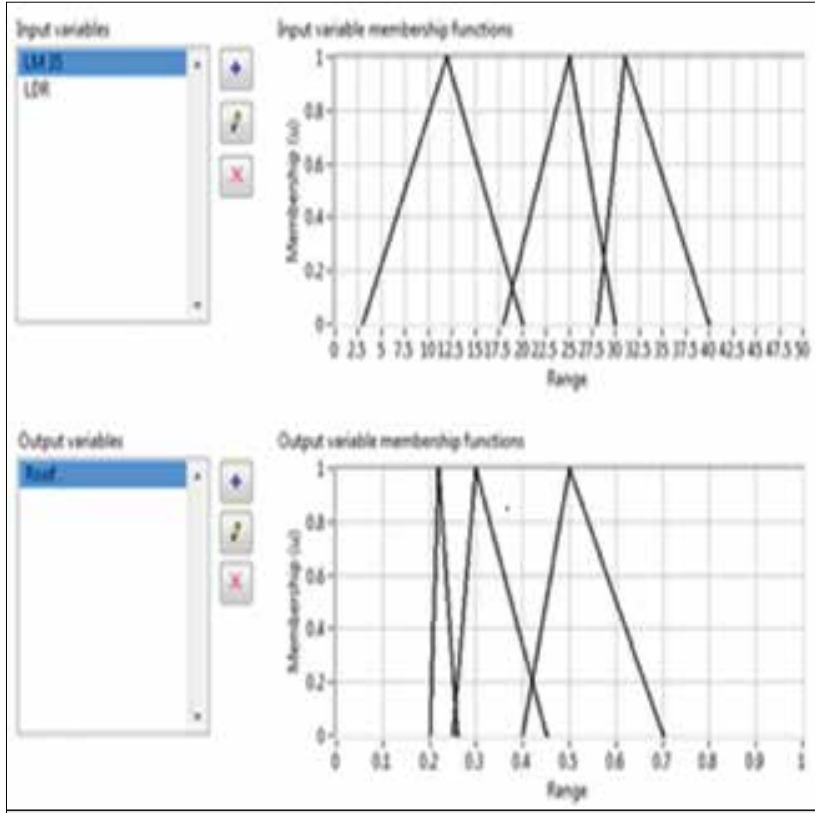

Figure 6. Fuzzy membership functions for rice

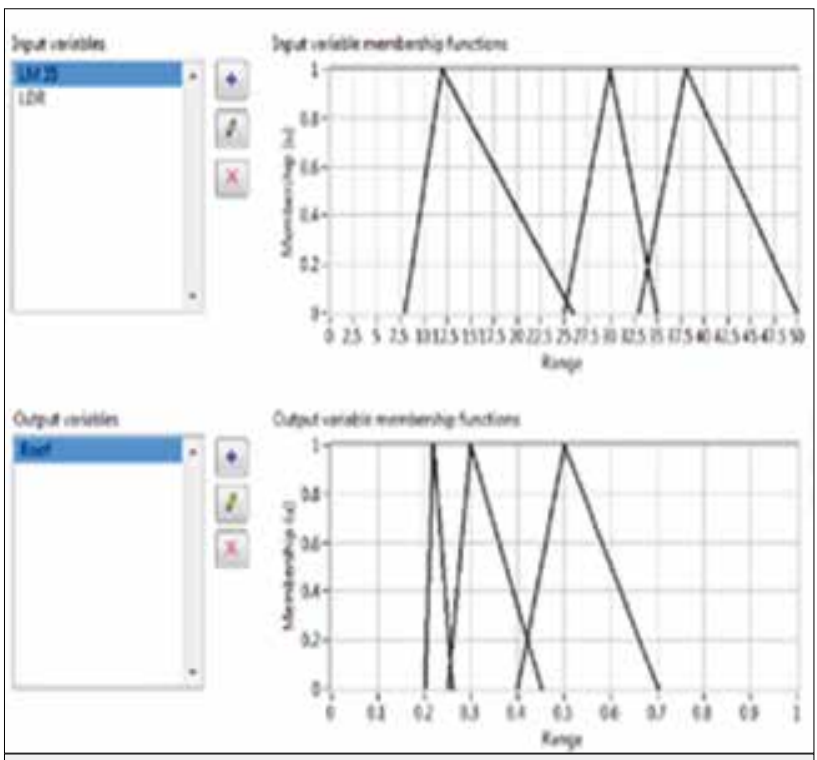

Figure 7. Fuzzy membership functions for wheat

\section{Results and discussion}

Data from four sensors like temperature, light, humidity and soil moisture sensors are displayed on the front panel of LabVIEW. There is a knob to change the fuzzy algorithm for different crops. The data from temperature, light, soil moisture and humidity sensor are given to fuzzy controller which controls the roof opening through servo motor, and water pump speed. Figure 8 shows one set of measured values: when temperature is medium $\left(25^{\circ} \mathrm{C}\right)$ and light is low (10 micro-mols/s) which results in roof being opened completely (Duty cycle $=1$ ) to provide proper light energy for photosynthesis on the other side

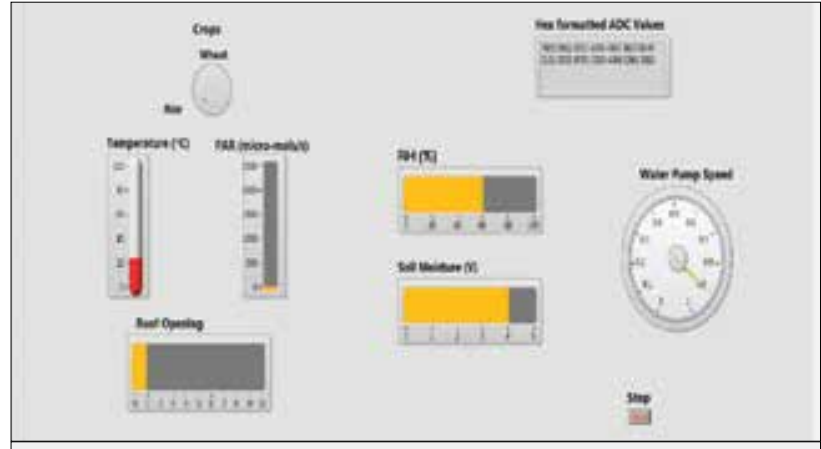

Figure 8. Front panel view of the proposed system interface

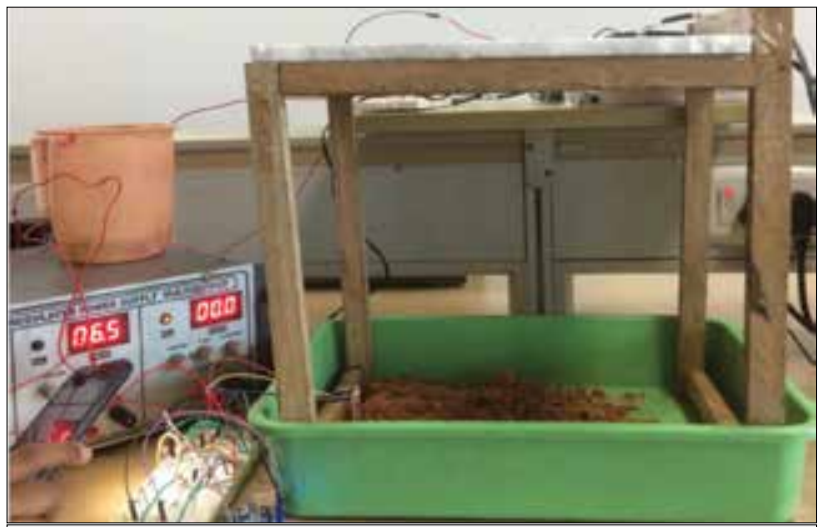

Figure 9. Laboratory setup showing closed roof

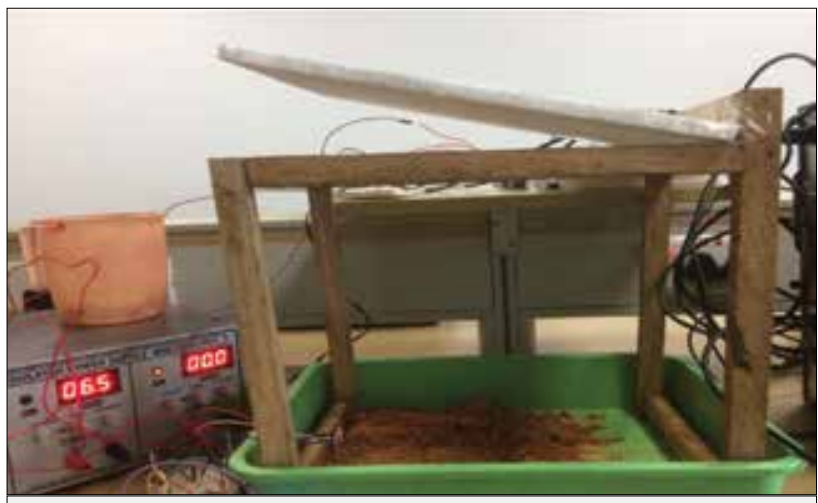

Figure 10. Model with roof partially opened

when humidity is medium (62 $\mathrm{RH} \%$ ) and soil moisture is high $(4 \mathrm{~V})$ it results in the water pump speed being reduced completely (Duty cycle $=0.9$ ) which provides optimized use of water.

Figure 9-11 shows different position of roof being close, partially open, and open respectively so as to control the variations of temperature and light in the surrounding. Figure 12 shows the connection of ZigBee to the sensors.

\section{Conclusion}

An Automatic Fuzzy Controller based Smart Agriculture System (AgriSys) is developed using NI myRIO. AgriSys mainly 


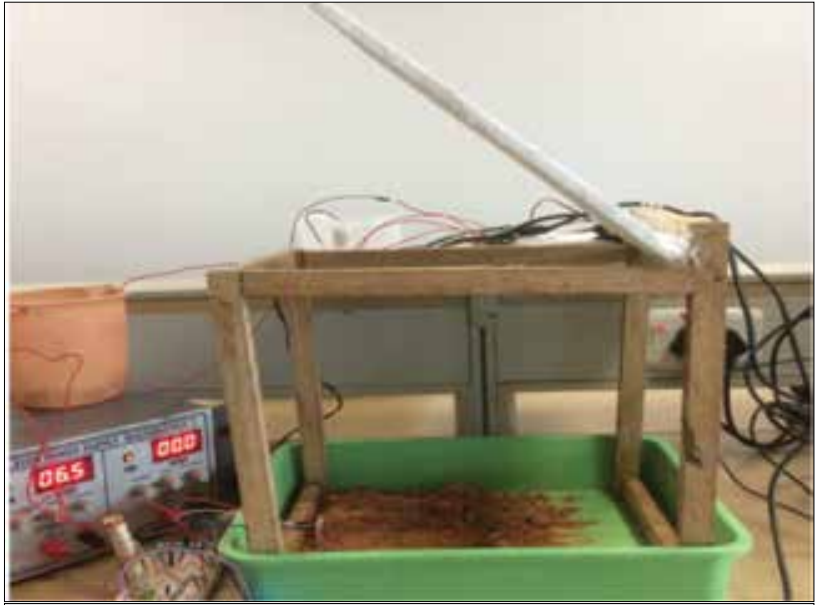

Figure 11. Model with fully opened roof

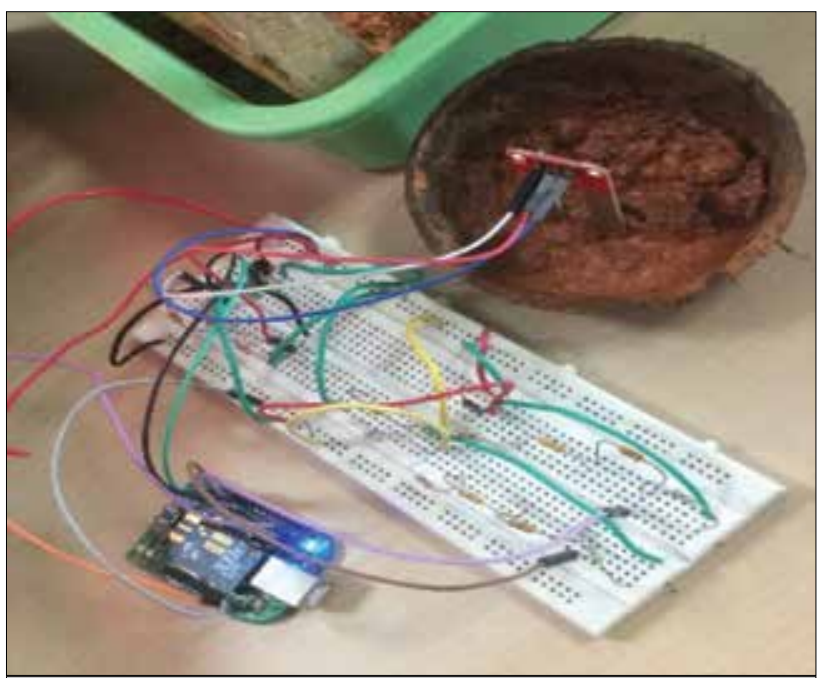

Figure 12. Placement and integration of humidity sensor

looks at inputs, such as temperature, light, humidity and soil moisture. Fuzzy controller is very robust and it can be easily modified. It can use multiple inputs and outputs sources. It is simple and very quick to implement. AgriSys can analyze an environment and intervene to maintain its adequacy. The system is easy to update and maintain over time and has an easy-to-upgrade bank of inference rules to control the agricultural environment. The system provides increased productivity and instant interventions and is able to automatically monitor the parameters and make necessary changes to the output. Incorporating Xbee makes it easier to send data to a remote place since the range of Xbee goes about more than $1000 \mathrm{~m}$.

\section{References}

1. X. Xu, X. Li, G. Qi, L. Tang, L. Mukwereza, “Science, Technology, and the politics of knowledge: The case of China's agricultural technology demonstration centers in Africa", World Development, vol. 81, pp. 82-91, 2016. [CrossRef]
2. J. W. Jones, J. M. Antle, B. Basso, K. J. Boote, R. T. Conant, I. Foster, H. C. J. Godfray, M. Herrero, R. E. Howitt, S. Janssen, B. A. Keating, R. Munoz-Carpena, C. H. Porter, C. Rosenweig, T. R. Wheeler, "Towards a new generation of agriculture system data, models, and knowledge products: State of agriculture systems science, Agriculture Systems, vol. 156, pp. 269-288, 2017. [CrossRef]

3. A. Chhetri, P. Aggarwal, P. K. Joshi, S. Vyas, "Farmer's prioritization of climate-smart agriculture (CSA) technologies", Agriculture Systems, vol. 151, pp. 184-191, 2017. [CrossRef]

4. C. Mwongera, K. M. Shikuku, J. Twyman, P. Laderach, E. Ampaire, P. V. Asten, S. Twomlow, L. A. Winowiecki, "Climate smart agriculture rapid appraisal (CSA-RA): A tool for prioritizing context-specific climate smart agriculture technologies, Agriculture Systems, vol. 154, pp. 192-203, 2017. [CrossRef]

5. M. Babulicova, "Enhancing of winter wheat productivity by the introduction of field pea into crop rotation", Agriculture, vol. 62, no. 3, pp. 101-110, 2016. [CrossRef]

6. J. Jones, J. Antle, B. Basso, K. Boote, R. Conant, I. Foster, T. Wheeler, "Brief history of agricultural systems modeling", Agriculture Systems, vol. 155, pp. 240-254, 2016. [CrossRef]

7. S. Far and K. Moghaddam, "Determinants of Iranian agricultral consultant's intentions toward precision agriculture:Integrating innovativeness to the technology acceptance model", Journal of the Saudi Society of Agriculture Science., vol. 16, pp. 280-286, 2017. [CrossRef]

8. S. Maurya and V. K. Jain, "Energy-efficient network protocol for precision agriculture", IEEE Consumer Electronics Magazine, vol. 17, pp. 42- 51, 2017. [CrossRef]

9. F. Viani, M. Bertolli, M. Salcucci, A. Polp, "Low cost wireless monitoring and decision support for water saving in agriculture", IEEE Sensors Journal, vol. 17, no. 13, pp. 4299-4309, 2017. [CrossRef]

10. S. Askraba, A. Paap, K. Alameh, J. Rowe, C. Miller, "Optimization of an optoelectronics-based plant real-time discrimination sensor for precision agriculture", Journal of Lightwave Technology, vol. 31, no. 5, pp. 822-829, 2013. [CrossRef]

11. M. Roopaei, P. Rad, K. Choo, "Cloud of things in smart agriculture:Intelligent irrigation monitoring by thermal imaging", IEEE Cloud Computing, vol. 4, no. 1, pp. 10-15, 2017. [CrossRef]

12. L. Zhou, N. Chen, Z. Chen, C. Xing, "ROSCC: An efficient remote sensing observation-sharing method based on cloud computing for soil moisture mapping in precsion agriculture", IEEE Journal of selected topics in applied earth observations and remote sensing, vol. 9, no. 12, pp. 5588-5598, 2016. [CrossRef]

13. P. Tokekar, J. Hook, D. Mulla, V. Isler, "Sensor planning for a Symbiotic UAV and UGV sytem for precision agriculture", IEEE Transactions on Robotics, vol. 32, no. 6, pp. 1498-1511, 2016. [CrossRef]

14. Y. Shouyi, L. Leibo, Z. Renyan, S. Zhongfu, W. Shaojun, “Design of wireless multimedia sensor network for precision agriculture", China Communications, vol. 10, no. 2, pp. 71-88, 2013. [CrossRef]

15. C. Deng, K. Wang, J. Li, G. Zhao, Z. Shanggun, "Effect of soil mositure and atmospheric humidity on both plant productivity and diversity of native grassland across the Loess Plateau,China", Ecological Engineering, vol. 94, pp. 525-531, 2016. [CrossRef]

16. Z. Mustaq, S. Sani, K. Hamed, A. Alil, S. Belal, A. Naqvi, "Agricultural land irrigation sysytem by fuzzy logic", International Conference on Information Science and Control Engineering, pp. 871-875, 2016.

17. S. Revathi, T. Radhakrishnan, N. Sivakumaran, "Climate control in greenhouse using intelligent control algorithms" American Control Conference, pp. 887-892, 2017. [CrossRef] 
18. J. Hatfield, J. Prueger, "Temperature extremes: Effect on plant growth and development", Weather and Climate Extremes, vol. 10, pp. 4-10, 2015. [CrossRef]

19. K. Barlowa, B. Chirsty, G. O'Leary, P. Riffkin, J. Nuttall, "Simulating the impact of extreme heat and frost events on wheat crop production:A review", Field Crops Research, vol. 171, pp. 109-119, 2015. [CrossRef]
20. S. Dwivedi, S. Kumar, V. Prakash, J. Mishra, "Effect of climate change on growth and physiology of rice-wheat genotypes", Conservation Agriculture, pp. 527-543, 2016. [CrossRef]

21. A. Sharififar, H. Ghorbani, H. Karim, "Integrated land evaluation for sustainable agricultural production by using analytical hierarchy process", Agriculture, vol. 59, no. 3, pp. 131-140, 2013. [CrossRef]

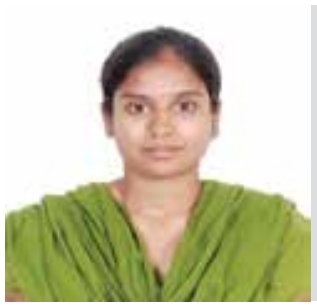

V Sravani is presently working as a faculty in of Manipal Institute of Technology, Manipal, India. She received her Bachelors and Masters from Jawaharlal Nehru Technological University, Hyderabad, India in year 2011 and 2013 respectively. She is currently pursuing her PhD in Manipal University, India. Her research interest are soft sensors, Computational Fluid Dynamics, and automation.

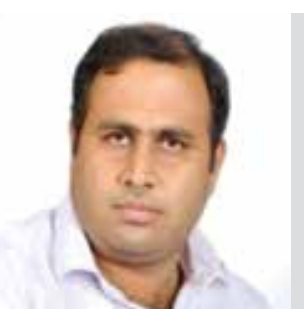

Santhosh KV is presently working as a faculty in Instrumentation and Control Engineering department of Manipal Institute of Technology, Manipal, India. He received his Bachelors and Masters from Visvesvaraya Technological University, Belgaum in year 2004 and 2006 respectively. He obtained PhD in the year 2013 from National Institute of Technology Silchar. His research interests include intelligent measurement, automation, sensor fusion, and image processing.

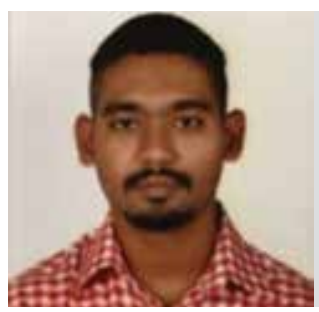

Sanjay Bhargava has received his Bachelors from Manipal Institute of Technology, Manipal in year 2017. Her area of interests are automation, LabVIEW.

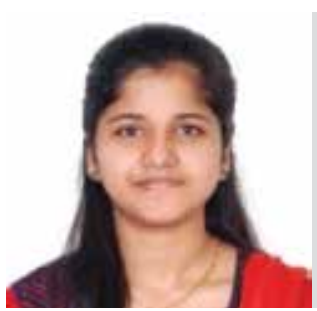

Verina Preema D'Almeida is presently working as a Associate Software Engineer in Accenture, Bangalore, India. She received her Bachelors from Manipal Institute of Technology, Manipal in year 2017. Her area of interests are automation, loT and PLC. 